2-2-7 鼓室成形手術の音響学的考察



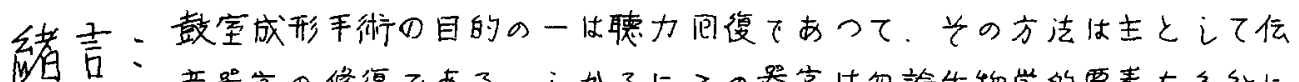
音器官の修復である。汃了にての器官は勿論生物学的要素を多引た

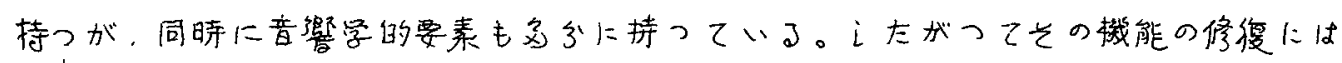

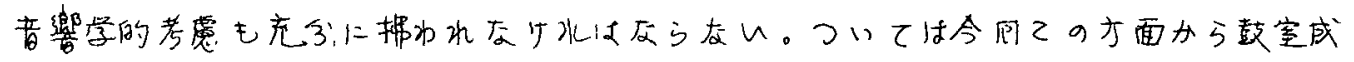

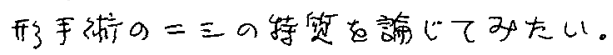

\title{
工: 鼓宝成开手唽における聴力包德の限界
}

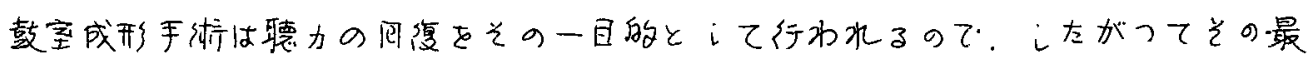

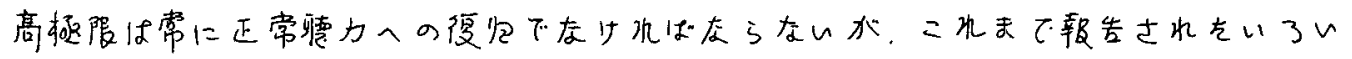

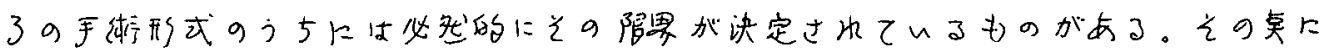
ついてまず考察する。

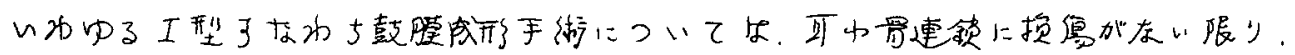

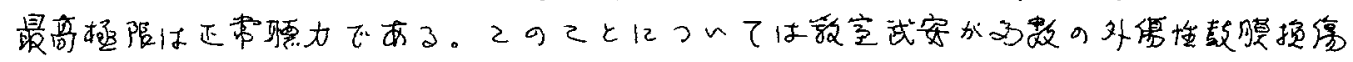

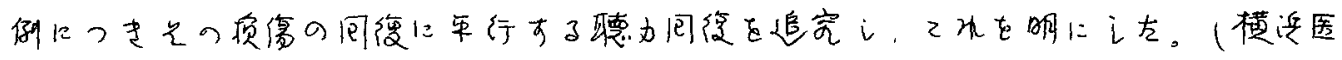





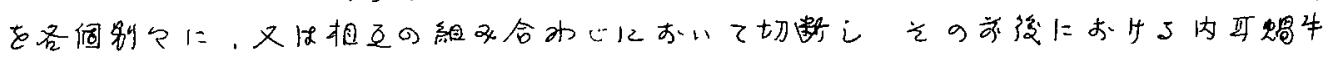

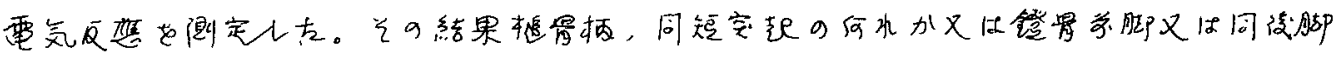

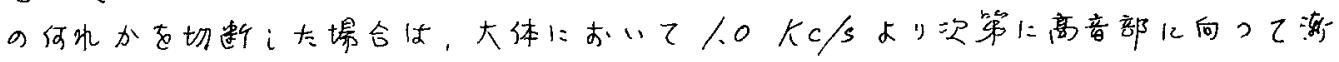

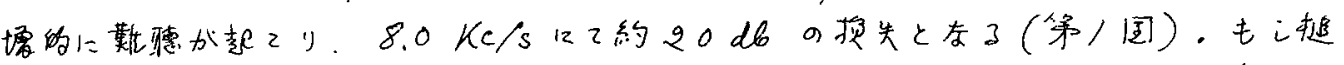



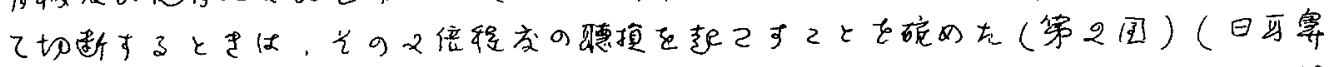

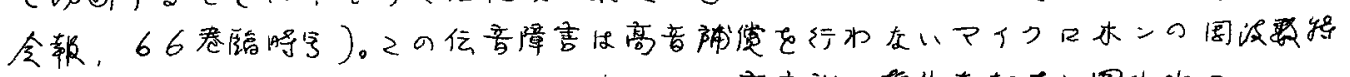

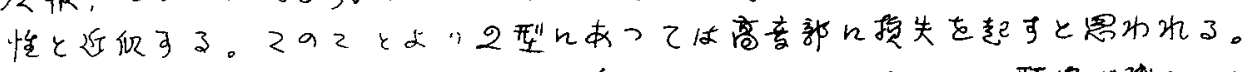

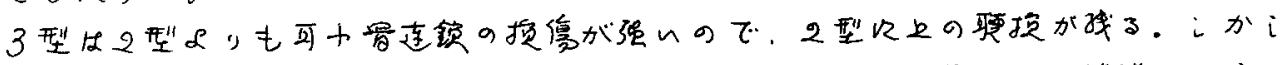

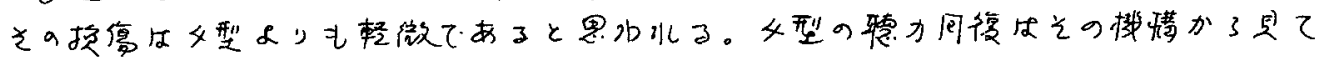

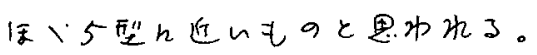

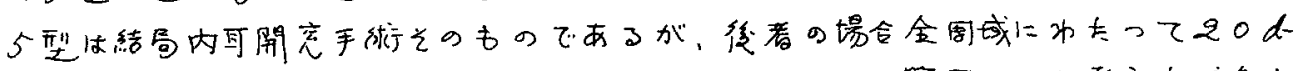

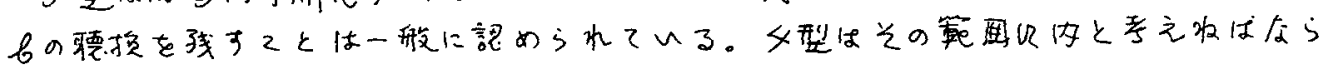

去。

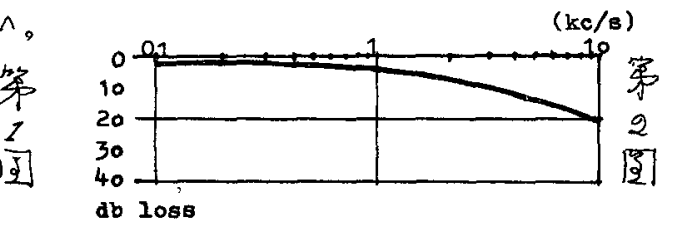

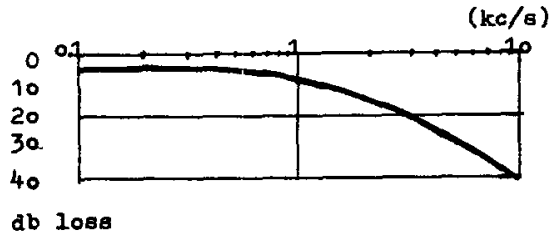

昭和 38 年 10 月 


\section{II、手街技法に圈する呼究補遺}

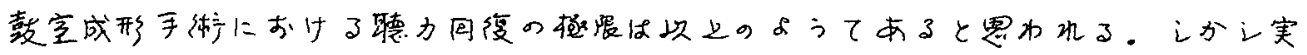

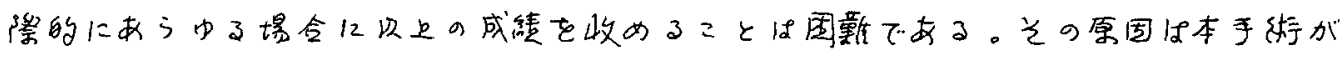

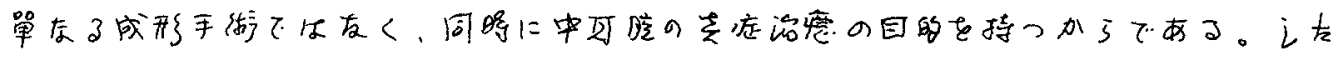

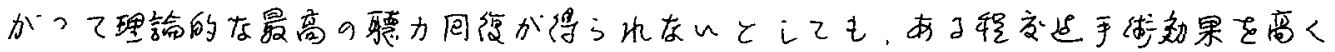





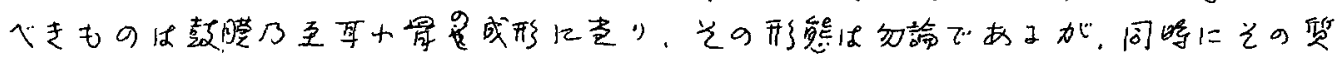

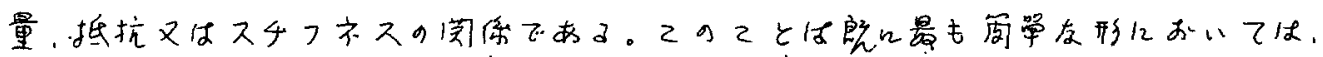



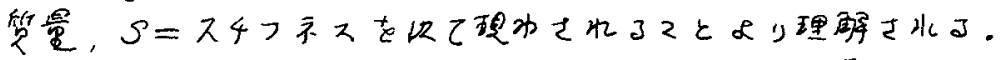

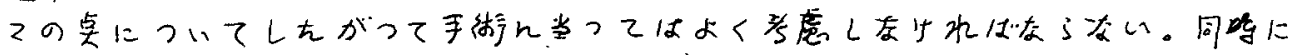



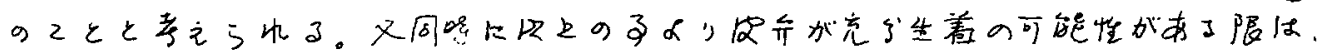


る限りにおいては牙復面の冰を用いるようんしている。

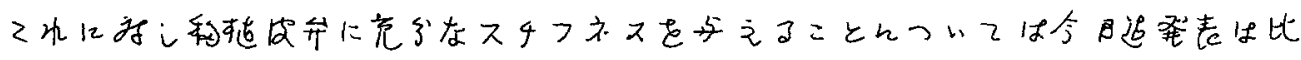

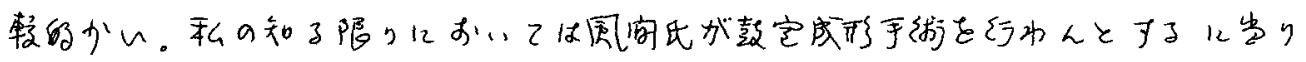

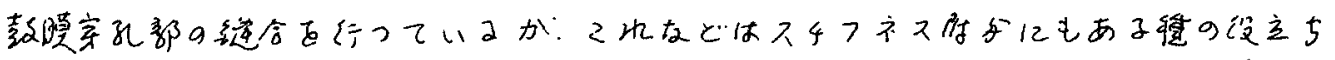

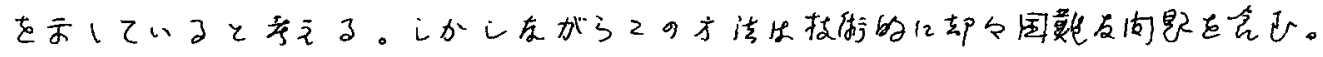

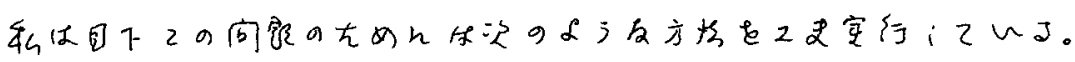

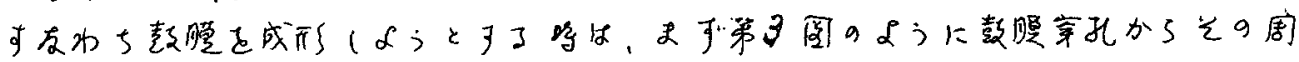

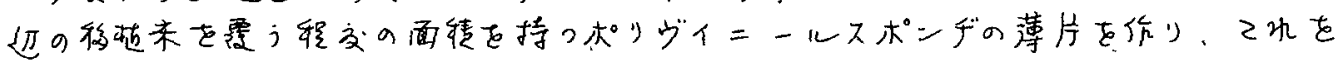



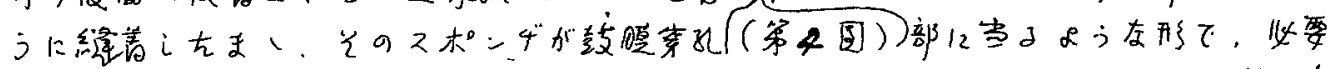

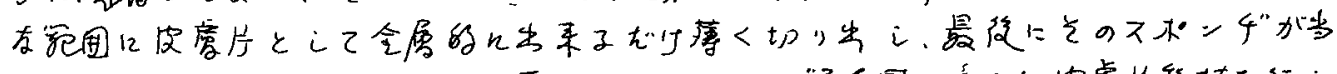



- 第3国第々国
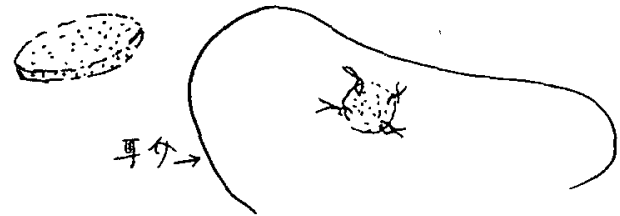

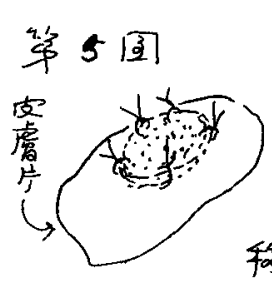

称和

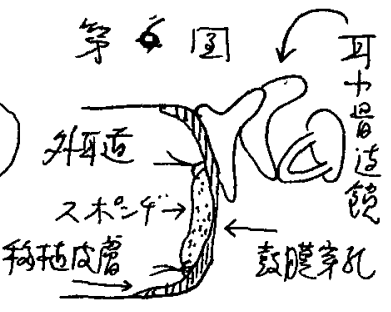

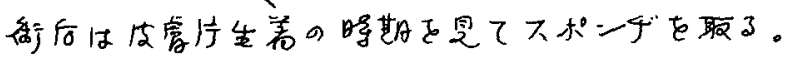

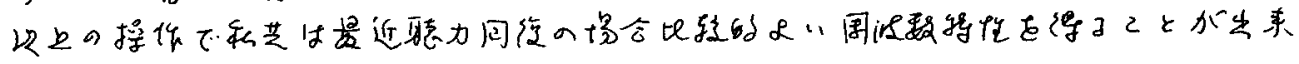
るようになつち。

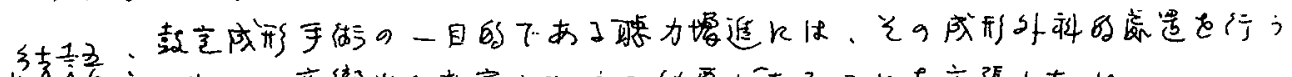



